\title{
Prevalence of Femoroacetabular Impingement Syndrome among Young and Middle-aged White Adults
}

\author{
Jacek A. Kopec (iD), Qian Hong (iD), Hubert Wong (iD, Charlie J. Zhang, Charles Ratzlaff(D),

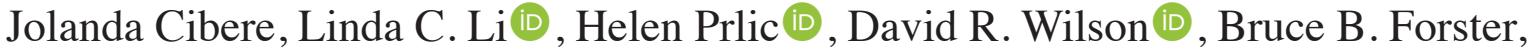 \\ and John M. Esdaile, for the IMPAKT-HIP Study Team
}

\begin{abstract}
Objective. The purpose of the study was to determine the prevalence of femoroacetabular impingement syndrome (FAIS) in white adults 20 to 49 years of age.

Methods. Participants were white men and women aged 20-49 years, recruited through random digit dialing from the population of Metro Vancouver, British Columbia, Canada. Participants filled out a self-administered questionnaire and underwent a physical examination and radiographs of both hips. FAIS was defined as a combination of hip symptoms, physical signs of impingement, and radiological findings of cam or pincer morphology as recommended by the Warwick Agreement. All analyses were weighted to reflect the population from which the sample was drawn.

Results. Data were obtained for 500 participants. In the study population, $48.9 \%$ were males and the age distribution was $32.2 \%, 31.4 \%$, and $36.4 \%$ in the groups 20-29, 30-39, and 40-49 years, respectively. The physical signs of impingement correlated significantly with symptoms, but there was no significant association between either symptoms or physical examination with radiographic findings. FAIS on either side was found in $3.0 \%$ (95\% CI 1.5-4.5) of the population.

Conclusion. In this study, FAIS was present in 3\% of whites aged 20-49 years. Further research is needed to develop consistent criteria for assessing hip symptoms, physical signs, and hip joint morphology, and to better understand the relationships between them. (First Release June 15 2020; J Rheumatol 2020;47:1440-5; doi:10.3899/jrheum.190345)
\end{abstract}

Key Indexing Terms:

FEMOROACETABULAR IMPINGEMENT SYNDROME PINCER MORPHOLOGY EPIDEMIOLOGY

CAM MORPHOLOGY HIP PAIN

FLEXION-ADDUCTION-INTERNAL-ROTATION TEST

Femoroacetabular impingement (FAI) is considered a risk factor for hip pain and osteoarthritis $(\mathrm{OA})^{1,2,3}$. In 2016, to clarify FAI-related concepts and terminology, an international panel of experts defined FAI syndrome (FAIS) as a "motion-related clinical disorder of the hip with a triad of symptoms, clinical signs and imaging findings" (Warwick Agreement $)^{4}$. Two types of imaging findings that may be associated with impingement are referred to as cam and

From the School of Population and Public Health, University of British Columbia, Vancouver; Arthritis Research Canada, Richmond, British Columbia; Centre for Health Evaluation and Outcome Sciences, St. Paul's Hospital; the Department of Medicine, and the Department of Physical Therapy, and the Department of Orthopaedics, and the Department of Radiology, University of British Columbia, Vancouver, British Columbia; Department of Family Medicine, University of Calgary, Calgary, Alberta, Canada; Arthritis Centre and College of Medicine, University of Arizona, Tucson, Arizona, USA.

The study was supported by Grant No. PAF-107513 from the Canadian Institutes of Health Research.

J.A. Kopec, MD, PhD, School of Population and Public Health, University of British Columbia, and Arthritis Research Canada; H. Qian, MSc, Centre for Health Evaluation and Outcome Sciences, St. Paul's Hospital; $H$. Wong, PhD, School of Population and Public Health, University of British Columbia; C.J. Zhang, MD, Department of Family Medicine, pincer morphology. Cam morphology is a flattening of the femoral head-neck junction whereas pincer morphology is characterized by acetabular over-coverage $e^{1,4,5}$. These features, in combination with some types of movements or positions, may lead to inappropriate contact between femoral head and acetabulum, eventually causing labral and cartilage damage $\mathrm{e}^{4,5}$.

To our knowledge, no study to date has provided 
information on the prevalence of FAIS as defined in the Warwick Agreement. A number of studies assessed the prevalence of cam and pincer morphology; although few were truly population-based, a wide variety of methods and definitions were used, and the results showed extreme variation, ranging from $5 \%$ to almost $100 \%{ }^{6,7,8}$. In addition, there is conflicting evidence on the correlation between symptoms, physical signs, and radiological measurements ${ }^{9,10}$. The purpose of our study was to estimate FAIS prevalence among white adults 20-49 years of age and investigate the relationships between the 3 components of FAIS (symptoms, physical signs, and imaging findings).

\section{MATERIALS AND METHODS}

Participants were white men and women aged 20-49 years, recruited through random digit dialing (RDD) from the population of Metro Vancouver, British Columbia, Canada, in March to November 2012. A stratified sample of persons with and without hip pain was obtained. To this end, randomly selected individuals were screened for hip symptoms by asking the following question: "At any time in the past 12 months, have you experienced any pain, stiffness or discomfort in your groin or the front of your upper thigh?", ${ }^{10}$ Followup questions asked whether symptoms lasted at least 6 weeks or occurred on 3 or more occasions. Pregnant women and persons with bilateral hip replacement were excluded. Subjects without hip pain were selected randomly once a sufficient number of persons with pain had been identified. Eligible subjects who agreed to participate in the study filled out a self-administered questionnaire, underwent a standardized physical examination by a physiotherapist, and obtained radiographs of both hips.

The main symptom of FAIS has been described as pain in the groin or hip, although some variation exists in precise location and precipitating factors ${ }^{4}$. In the current study, we were interested in persistent or recurrent symptoms from the hip joint. In the self-administered questionnaire, we repeated the screening questions about hip symptoms and obtained additional details about the location of pain/stiffness/discomfort and other variables. In particular, body mass index (BMI) was calculated based on self-reported height and weight, and hip injury was assessed by asking, "Have you ever had a hip injury that required you to use a walking aid (e.g., cane or crutch) for at least one week?" We also asked which hip was injured and age at the time of injury (first injury in case of multiple injuries).

As part of the physical examination, we performed the flexion-adduction-internal-rotation (FADIR) test on both hips ${ }^{11,12}$. Following the assessment protocol ${ }^{12}$, the subject was in a supine position and aligned to the lateral edge of the examination table. The examiner was standing on the ipsilateral side of the hip to be examined and passively flexed the hip and knee to $90^{\circ}$. The examiner adducted the hip to the endpoint and then internally rotated the hip, maintaining flexion and adduction components. The examiner asked the subject if they "feel pain or discomfort in the inner thigh, upper thigh or groin area." Nine physiotherapists (PT) conducted the physical examination. Prior to the study, CR (an experienced researcher and PT) led a training session with 7 PT and 2 rheumatologists that introduced a standardized description of each test, a standardized script for asking patient questions, demonstration of each test, and practice with feedback. In a previously reported interrater reliability study, which included 4 of the 9 PT participating in the current study, we found overall agreement of 0.76 (0.66-0.91), negative agreement of $0.79(0.60-0.93)$, and positive agreement of $0.73(0.58-0.89)$, indicating that the test was reliable ${ }^{12}$.

Standardized radiographs of the pelvis with anteroposterior (AP) view and Dunn views of both hips were obtained as described in detail in previous publications ${ }^{10,11,12,13}$. For the AP pelvis view, the subject was in a weight-bearing position, with legs internally rotated $15^{\circ}$. For the bilateral Dunn view, the subject was supine and the hip was positioned in $45^{\circ}$ flexion and $20^{\circ}$ abduction while maintaining neutral rotation ${ }^{14}$. Cam morphology was defined as alpha angle $>60^{\circ 10,15}$ on the Dunn view, while pincer morphology was defined as lateral center edge (LCE) angle $>40^{\circ}$ on the AP view ${ }^{8}$. All radiographic measurements were performed by a single, trained reader. In a reliability study in 49 subjects with the same reader, the intrarater intraclass correlation coefficient was 0.97 for the alpha angle and 0.87 for the LCE angle ${ }^{13}$. All subjects provided informed consent and the study was approved by the University of British Columbia Clinical Research Ethics Board (No. H11-00868).

Statistical methods. All statistical analyses were performed using Proc Survey procedures in SAS (version 9.4, SAS Institute Inc.) to account for sampling weights. Sampling weights were used to adjust for the design of the survey (stratified sampling) and nonresponse in terms of age, sex, and hip pain status, followed by a post-stratification to reflect the age and sex distribution of the population of Metro Vancouver. Descriptive statistics included means and proportions with 95\% CI. FAIS was defined as coexistence of symptoms, positive FADIR, and cam or pincer morphology in the same hip. We used a Venn diagram to visually present the relationships between these components. Associations between symptoms, physical signs, and cam/pincer morphology, were analyzed in logistic regression adjusting for age, sex, and BMI. In the analysis combining both hips, each participant was treated as a cluster. In addition, we carried out the analyses separately for left and right hip.

\section{RESULTS}

Using RDD, we obtained a sample of 858 potential subjects and were able to contact 754 (87.9\%). However, 254 (33.7\%) of those did not provide data: 41 were ineligible, 66 not interested, 84 not available, 53 declined for other/unknown reasons, and 10 were excluded owing to incomplete data. Data were obtained from 500 participants. Descriptive data for the study sample and weighted data reflecting the study population are given in Table 1.

In the study population, 48.9 were males; $32.2,31.4$, and 36.4 were $20-29,30-39$, and 40-49 years old, respectively; $44.9 \%$ had college/university education; $15.1 \%$ were

Table 1. Descriptive data for the study sample $(\mathrm{n}=500)$.

\begin{tabular}{lcc}
\hline Variables & $\mathrm{N}(\%)$ & Weighted \% (95\% CI)* \\
\hline Sex & & \\
$\quad$ Male & $181(36.2)$ & $48.9(41.6-56.2)$ \\
$\quad$ Female & $319(63.8)$ & $51.1(43.8-58.4)$ \\
Age, yrs & & \\
$\quad 20-29$ & $50(10.0)$ & $32.2(23.8-40.6)$ \\
$30-39$ & $109(21.8)$ & $31.4(25.1-37.7)$ \\
$\quad 40-49$ & $341(68.2)$ & $36.4(30.5-42.3)$ \\
Education & & \\
$\quad$ High school or less (grades 0-13) & $101(20.2)$ & $27.3(20.0-34.6)$ \\
$\quad$ Vocational or some college & $178(35.6)$ & $27.8(21.8-33.7)$ \\
$\quad$ College or university & $221(44.2)$ & $44.9(37.7-52.1)$ \\
BMI & & \\
$\quad<25$ & $241(48.2)$ & $58.8(51.9-65.6)$ \\
25-29.9 & $155(31.0)$ & $26.1(20.3-31.9)$ \\
$\quad 30+$ & $104(20.8)$ & $15.1(10.6-19.6)$ \\
Hip injury & & \\
$\quad$ Yes & $26(5.2)$ & $2.0(0.8-3.1)$ \\
$\quad$ No & $474(94.8)$ & $98.0(96.9-99.2)$ \\
\hline
\end{tabular}

* Weighted data adjust for oversampling of persons with pain to reflect population prevalence. BMI: body mass index.

Personal non-commercial use only. The Journal of Rheumatology Copyright $\subset$ 2020. All rights reserved. 
obese (BMI > 30); and 2.0\% reported a hip injury in the past (Table 1). Only $1.1 \%$ reported being diagnosed with hip OA. Persistent or recurrent hip joint symptoms on either side were present in $28.1 \%$ (95\% CI 22.3-33.8) of the population; $21.9 \%$ in men and $34.0 \%$ in women (Table 2).

A positive FADIR test on either side was found in 34.3\% (27.6-41.1); $35.7 \%$ in men and $33.1 \%$ in women. The distribution of alpha angle was strongly skewed, while the LCE angle was symmetrically distributed. Cam morphology, defined as alpha angle $>60^{\circ}$ on either side, was observed in $20.5 \%$ (14.1-26.9) of the population, $35.1 \%$ and $6.6 \%$ in men and women, respectively. Pincer morphology (LCE angle $>40^{\circ}$ ) was present in $7.6 \%$ (3.9-11.4); $9.8 \%$ in men and $5.6 \%$ in women (Table 2).

FAIS on either side was found in $3.0 \%(1.5-4.5)$ of the population; $3.4 \%$ in men and $2.7 \%$ in women. In Figure 1 we show the weighted percentages of all combinations of the 3 components of FAIS, separately for the left and right hip, in a Venn diagram. Prevalence of FAIS was $1.9 \%$
(0.63-3.2) on the left side and $2.1 \%(0.80-3.5)$ on the right side.

After adjusting for age, sex, and BMI, prevalence of cam/pincer morphology was not significantly different in persons with versus without symptoms in the same hip (OR $0.71,95 \%$ CI $0.38-1.34$ ) or in persons with versus without a positive FADIR test (OR 1.01, 95\% CI 0.53-1.90; Table 3). Hip symptoms and FADIR test were strongly and significantly correlated (OR 3.98, 2.49-6.36). When the data were analyzed separately for the left and right hip, the results were similar.

\section{DISCUSSION}

To our knowledge, this is the first large study in a random population sample to determine the prevalence of FAIS that applied the definition proposed in the Warwick Agreement. FAIS was defined in this study as coexistence of hip symptoms (persistent or recurrent pain, stiffness, or discomfort in the groin or upper thigh), positive impingement sign

Table 2. Sampling weighted prevalence (95\% CI) of hip symptoms, positive FADIR test, cam/pincer morphology, and FAIS (in either hip).

\begin{tabular}{lccc}
\hline Variables & Male & Female & All \\
\hline Any hip pain & $21.9(15.1-28.7)$ & $34.0(25.4-42.6)$ & $28.1(22.3-33.8)$ \\
Positive FADIR & $35.7(25.3-46.2)$ & $33.1(24.3-41.8)$ & $34.3(27.6-41.1)$ \\
Cam morphology & $35.1(23.9-46.3)$ & $6.6(1.9-11.3)$ & $20.5(14.1-26.9)$ \\
Pincer morphology & $9.8(3.0-16.6)$ & $5.6(2.4-8.8)$ & $7.6(3.9-11.4)$ \\
Cam or pincer & $39.1(27.9-50.3)$ & $12.2(6.6-17.8)$ & $25.3(18.7-31.9)$ \\
FAIS & $3.4(1.3-5.4)$ & $2.7(0.5-4.8)$ & $3.0(1.5-4.5)$ \\
\hline
\end{tabular}

Cam morphology is defined as alpha angle $>60^{\circ}$ and pincer morphology is defined as LCE angle $>40^{\circ}$. FADIR: flexion-adduction-internal-rotation test; FAIS: femoroacetabular impingement syndrome; LCE: lateral center edge.

\section{Left side}

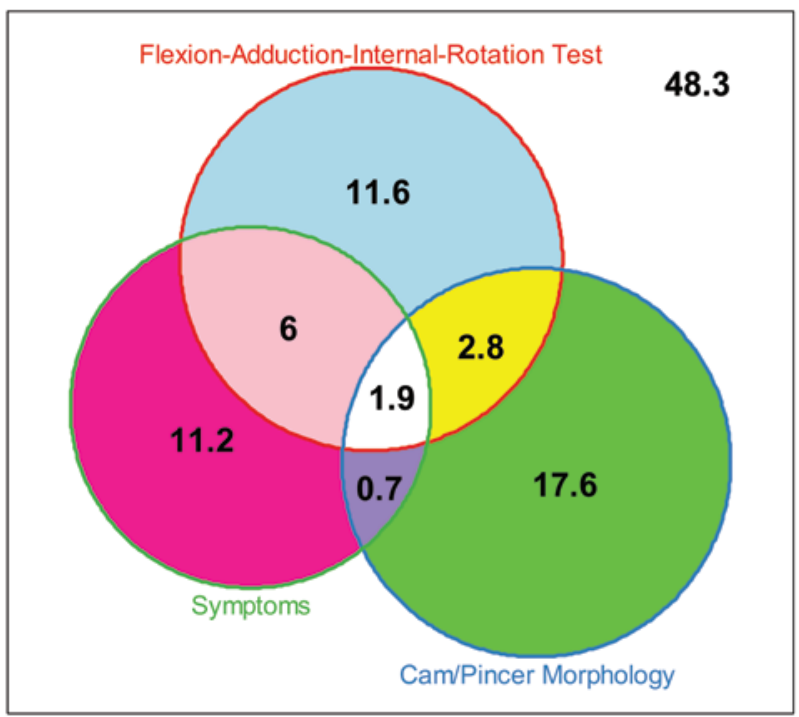

Right side

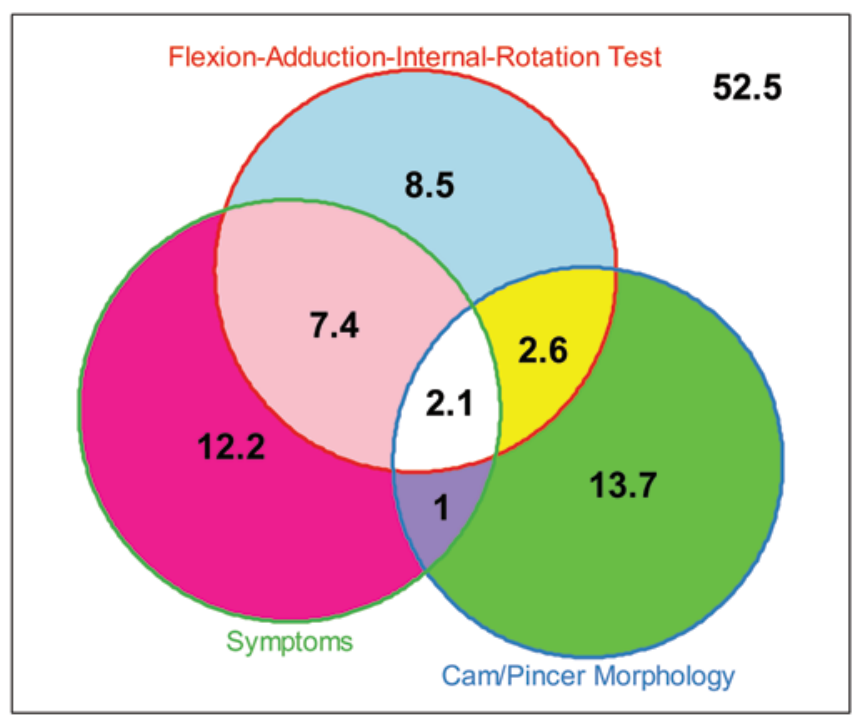

Figure 1: Overlap between hip pain, FADIR test, and cam/pincer morphology (numbers are weighted percentages). FADIR: flexion-adduction-internal-rotation.

Personal non-commercial use only. The Journal of Rheumatology Copyright $(\subset) 2020$. All rights reserved. 
Table 3. Relationships between hip symptoms, FADIR test, and cam/pincer morphology.

\begin{tabular}{lccc}
\hline Outcomes & Comparison & OR & 95\% CI \\
\hline Two sides combined & & & \\
$\quad$ FADIR test & Symptoms (+) vs Symptoms (-) & 3.98 & $2.49-6.36$ \\
Cam/pincer morphology & Symptoms (+) vs Symptoms (-) & 0.71 & $0.38-1.34$ \\
Cam/pincer morphology & FADIR (+) vs FADIR (-) & 1.01 & $0.53-1.90$ \\
Left side & Symptoms (+) vs Symptoms (-) & 3.22 & $1.63-6.34$ \\
FADIR test & Symptoms (+) vs Symptoms (-) & 0.64 & $0.31-1.33$ \\
Cam/pincer morphology & FADIR (+) vs FADIR (-) & 0.86 & $0.39-1.88$ \\
Cam/pincer morphology & Symptoms (+) vs Symptoms (-) & 5.26 & $2.60-10.64$ \\
Right side & Symptoms (+) vs Symptoms (-) & 0.81 & $0.41-1.60$ \\
FADIR test & FADIR (+) vs FADIR (-) & 1.18 & $0.51-2.78$ \\
Cam/pincer morphology & & \\
Cam/pincer morphology &
\end{tabular}

Cam morphology was defined as alpha angle $>60^{\circ}$ and pincer morphology was defined as LCE angle $>40^{\circ}$. OR were obtained from logistic regression adjusted for age, sex, and BMI. FADIR: flexion-adduction-internalrotation test; LCE: lateral center edge; BMI: body mass index.

(FADIR test) on physical examination, and evidence of cam (alpha angle $>60^{\circ}$ in the Dunn view) or pincer (LCE angle $>40^{\circ}$ in the AP view) morphology in the same hip. We found FAIS in $3 \%$ of the white population of Metro Vancouver aged 20-49 years. Each of the individual components was present in $25-34 \%$ of the population. FADIR test was associated significantly with symptoms, but there was no significant correlation between either symptoms or FADIR and radiological evidence of cam or pincer morphology in the same hip.

Prevalence of hip symptoms in our study was higher than in previous published reports, especially among women. Most previous studies have been done in older populations ${ }^{16,17,18,19,20}$. Kim, et $a l^{16}$ reported prevalence of $14.7 \%$ in men and $24.7 \%$ in women aged 50+ in the Framingham Osteoarthritis Study, and $18.5 \%$ and $27.5 \%$, respectively, in the Osteoarthritis Initiative. In European studies, prevalence tended to be lower and ranged from $7.0-18.8 \%$ in men and $10.0-21.0 \%$ in women ${ }^{17,18,19,20}$. A population survey of adults in Canada found a prevalence of $20.0 \%$ in men and $27.0 \%$ in women ${ }^{21}$. In addition to population differences, different wording of the questions (e.g., inclusion of stiffness and discomfort in our study) might have influenced these findings.

In our study, prevalence of a positive clinical test (FADIR test) was higher than in previous studies, which is consistent with a relatively high frequency of hip symptoms. Physical examination plays an important role in the definition of FAIS and several impingement tests have been described in the literature ${ }^{4,11,22}$. For the current study, we selected the FADIR test because it has been recommended by an international panel of experts ${ }^{4}$, is reliable ${ }^{11,12,22}$, and is commonly used by clinicians $^{4,23}$. However, prevalence of a positive FADIR test in the general population is not well established. In a study among healthy young men and women, Laborie, et $a l^{24}$ found prevalence on either side to be $7.3 \%$ in men and $4.8 \%$ in women. Czuppon, et $a l^{25}$ reported higher prevalence in asymptomatic athletes, $12.2 \%$ in men and $15.3 \%$ in women.

Our findings of prevalence of cam and pincer morphology fall about in the middle of the large range reported in the literature for various populations. However, comparisons of our data with published data are limited because of a high degree of heterogeneity, as demonstrated in more recent reviews ${ }^{6,7,8}$. For example, prevalence of cam morphology varied from 5-75\% in a review of 30 studies by Dickenson, et $a l^{7}$. Cam morphology is usually based on alpha angle and this extreme variation in prevalence is likely due to differences in populations, imaging method (AP, frog lateral, cross-table lateral, and Dunn lateral radiographs, computed tomography, and magnetic resonance), and the cutoff value. In the aforementioned review, the cutoff value varied from $50-83^{\circ}$ and none of the studies was population-based ${ }^{7}$.

For pincer morphology, prevalence depends largely on the radiological features being considered, most of which are qualitative and not highly reliable ${ }^{13}$. Therefore, we selected a quantitative measure (LCE angle) with good reliability and a well-established cutoff value ${ }^{8}$. Nonetheless, prevalence of pincer morphology based on LCE angle $\geq 40^{\circ}$ varied in published studies from $5.8 \%$ to $29.7 \%$ in males and $2.0 \%$ to $35.1 \%$ in females ${ }^{26,27}$. Among adults, de Bruin, et a ${ }^{28}$ reported LCE angle $\geq 40^{\circ}$ in $22.6 \%$ of men and $17.3 \%$ of women, whereas Diese ${ }^{29}$ found overall prevalence to be $10.9 \%$. Thus, our results are within the range reported by other authors. The mean alpha and LCE angles in our study were also similar to those found by others ${ }^{6}$.

In the current study, frequency of radiographic evidence of cam or pincer morphology was not different in persons with and without hip symptoms. This is consistent with several published reports ${ }^{30,31,32,33,34}$. However, some studies reported a significant correlation between symptoms and alpha angle $35,36,37$. This discrepancy may be due to several factors, including the type of population being studied,

Personal non-commercial use only. The Journal of Rheumatology Copyright $@$ C 2020. All rights reserved. 
non-linear characteristics of the relationship, dilution of effect because of measurement errors, and small sample size in many studies ${ }^{10}$. In a prior study, we observed a non-linear relationship between alpha angle (treated as a continuous variable) and patient-reported outcomes ${ }^{10}$. On the other hand, no study so far has demonstrated a correlation between symptoms and isolated pincer morphology or high LCE angle.

The relationship between various physical maneuvers, including FADIR, with cam or pincer morphology has been studied clinically to assess the validity of these tests against imaging data ${ }^{11,22}$. Unfortunately, the quality of such studies has been poor and the data show extreme heterogeneity ${ }^{22}$. Our study, in contrast, assessed the relationship between FADIR and cam/pincer morphology in the general population. The high prevalence of a positive test and lack of a significant association with radiological measures is consistent with data suggesting that the test is sensitive but non-specific, and is likely to detect changes that may not be seen on radiographs ${ }^{11,22}$. In one previous population study ${ }^{24}$, FADIR was related to pain in women but not in men and was not related to alpha angle or other measures of cam or pincer morphology, except an association with a cam "composite score" in men.

The relationship between cam and pincer morphology with age and sex has been studied by several authors, as reviewed by van Klij, et $a l^{8}$. Consistently with the literature $\mathrm{r}^{6,7,8,16,17,18,19}$, our study found cam to be more common in men while hip pain was more common in women. The effect of age on cam/pincer morphology in adults is less clear ${ }^{8}$, but hip symptoms in the general population tend to increase with age $\mathrm{e}^{17}$.

Some methodological strengths and limitations of the study are important to mention. The sample was relatively large and the data were weighted to be representative of the general white population of Metro Vancouver. Since ethnicity has been shown to be a risk factor for impingement, our results should not be generalized to non-white populations. Subjects underwent comprehensive assessment that included both AP and Dunn views of both hips, standardized physical examination, and a self-administered questionnaire. Interrater agreement of cam and pincer measurements and the FADIR test was high. Comparisons with other studies are limited because of differences in definitions and methods. Agreed upon definitions, criteria, or cutoff values for each of the 3 components of FAIS do not currently exist ${ }^{4}$. Hip symptoms and a positive FADIR test were relatively common in our sample. Our results for cam and pincer morphology were within the range observed in the literature.

Prevalence of FAIS in this study was estimated to be $3 \%$. We used the Warwick Agreement definition of FAIS as a triad of symptoms, physical signs, and imaging findings. Current challenges in applying this definition include the lack of agreement on the best method to measure each element of this triad and incomplete understanding of the relationships between them.

\section{ACKNOWLEDGMENT}

The authors thank Morgan Barber for her help in data collection.

\section{REFERENCES}

1. Ganz R, Parvizi J, Beck M, Leunig M, Notzli H, Siebenrock KA. Femoroacetabular impingement: a cause for osteoarthritis of the hip. Clin Orthop Relat Res 2003;417:112-20.

2. Leunig M, Ganz R. Femoroacetabular impingement: a common cause of hip complaints leading to arthrosis. [Article in German] Unfallchirurg 2005;108:9-17.

3. Agricola R, Heijboer MP, Bierma-Zeinstra SM, Verhaar JA, Weinans H, Waarsing JH. Cam impingement causes osteoarthritis of the hip: a nationwide prospective cohort study (CHECK). Ann Rheum Dis 2013;72:918-23.

4. Griffin DR, Dickenson EJ, O’Donnell J, Agricola R, Awan T, Beck M, et al. The Warwick Agreement on femoroacetabular impingement syndrome (FAI syndrome): an international consensus statement. Br J Sports Med 2016;50:1169-76.

5. Ganz R, Leunig M, Leunig-Ganz K, Harris WH. The etiology of osteoarthritis of the hip: an integrated mechanical concept. Clin Orthop Relat Res 2008;466:264-72.

6. Frank JM, Harris JD, Erickson BJ, Slikker W 3rd, Bush-Joseph CA, Salata MJ, et al. Prevalence of femoroacetabular impingement imaging findings in asymptomatic volunteers: a systematic review. Arthroscopy 2015;31:1199-204.

7. Dickenson E, Wall PD, Robinson B, Fernandez M, Parsons H, Buchbinder R, et al. Prevalence of cam hip shape morphology: a systematic review. Osteoarthritis Cartilage 2016;24:949-61.

8. van Klij P, Heerey J, Waarsing JH, Agricola R. The prevalence of cam and pincer morphology and its association with development of hip osteoarthritis. J Orthop Sports Phys Ther 2018;48:230-8.

9. Kopec JA, Cibere J, Li LC, Zhang C, Barber M, Qian H, et al; IMPAKT-HIP Study Team. Relationship between physical activity and hip pain in persons with and without cam or pincer morphology: a population-based case-control study. Osteoarthritis Cartilage 2017;25:1055-61.

10. Kopec JA, Qian H, Cibere J, Wong H, Li LC, Barber M, et al; IMPAKT-HIP Study Team. Relationship between hip morphology and hip-related patient-reported outcomes in young and middle-aged individuals: a population-based study. Arthritis Care Res 2019;71:1202-8.

11. Tijssen M, van Cingel R, Willemsen L, de Visser E. Diagnostics of femoroacetabular impingement and labral pathology of the hip: a systematic review of the accuracy and validity of physical tests. Arthroscopy 2012;28:860-71.

12. Ratzlaff C, Simatovic J, Wong H, Li L, Ezzat A, Langford D, et al. Reliability of hip examination tests for femoroacetabular impingement. Arthritis Care Res 2013;65:1690-6.

13. Ratzlaff C, Zhang C, Korzan J, Josey L, Wong H, Cibere J, et al. The validity of a non-radiologist reader in identifying cam and pincer femoroacetabular impingement (FAI) using plain radiography. Rheumatol Int 2016;36:371-6.

14. Tannast M, Siebenrock KA, Anderson SE. Femoroacetabular impingement: radiographic diagnosis--what the radiologist should know. Am J Roentgenol 2007;188:1540-52.

15. Agricola R, Waarsing JH, Thomas GE, Carr AJ, Reijman M, Bierma-Zeinstra SM, et al. Cam impingement: defining the presence of a cam deformity by the alpha angle: data from the CHECK cohort and Chingford cohort. Osteoarthritis Cartilage 2014;22:218-25.

Personal non-commercial use only. The Journal of Rheumatology Copyright @ 2020 . All rights reserved. 
16. Kim C, Nevitt MC, Niu J, Clancy MM, Lane NE, Link TM, et al. Association of hip pain with radiographic evidence of hip osteoarthritis: diagnostic test study. BMJ 2015;351:h5983.

17. Birrell FN, Croft P, Cooper C, Hosie G, Macfarlane GJ, Silman AJ Radiographic change is common in new presenters in primary care with hip pain. Rheumatology 2000;39:772-5

18. Dawson J, Linsell L, Zondervan K, Rose P, Randall T, Carr A, et al. Epidemiology of hip and knee pain and its impact on overall health status in older adults. Rheumatology 2004;43:497-504.

19. Thiem U, Lamsfuß R, Günther S, Schumacher J, Bäker C, Endres $\mathrm{HG}$, et al. Prevalence of self-reported pain, joint complaints and knee or hip complaints in adults aged $\geq 40$ years: a cross-sectional survey in Herne, Germany. PLoS One 2013;8:e60753.

20. Cecchi F, Mannoni A, Molino-Lova R, Ceppatelli S, Benvenuti E, Bandinelli S, et al. Epidemiology of hip and knee pain in a community based sample of Italian persons aged 65 and older. Osteoarthritis Cartilage 2008;16:1039-46.

21. Kopec JA, Heath A, Sayre EC, Cibere J, Li LC, Marra CA, et al. Prevalence of joint pain and self-reported osteoarthritis in British Columbia, Canada. Ann Rheum Dis 2014;73 Suppl 2:257.

22. Shanmugaraj A, Shell JR, Horner NS, Duong A, Simunovic N, Uchida $S$, et al. How useful is the flexion-adduction-internal rotation test for diagnosing femoroacetabular impingement: a systematic review. Clin J Sport Med 2020;30:76-82.

23. Peters S, Laing A, Emerson C, Mutchler K, Joyce T, Thorborg K, et al. Surgical criteria for femoroacetabular impingement syndrome: a scoping review. Br J Sports Med 2017;51:1605-10.

24. Laborie LB, Lehmann TG, Engesæter I, , Engesæter LB, Rosendahl K. Is a positive femoroacetabular impingement test a common finding in healthy young adults? Clin Orthop Relat Res 2013;471:2267-77.

25. Czuppon S, Prather H, Hunt DM, Steger-May K, Bloom NJ, Clohisy JC, et al. Gender-dependent differences in hip range of motion and impingement testing in asymptomatic college freshman athletes. PM R 2017;9:660-7.

26. Li Y, Helvie P, Mead M, Gagnier J, Hammer MR, Jong N. Prevalence of femoroacetabular impingement morphology in asymptomatic adolescents. J Pediatr Orthop 2017;37:121-6.

27. Monazzam S, Bomar JD, Dwek JR, Hosalkar HS, Pennock AT. Development and prevalence of femoroacetabular impingement-associated morphology in a paediatric and adolescent population: a CT study of 225 patients. Bone Joint J 2013; 95-B:598-604.
28. de Bruin F, Reijnierse M, Farhang-Razi V, Bloem JL. Radiographic signs associated with femoroacetabular impingement occur with high prevalence at all ages in a hospital population. Eur Radiol 2013;23:3131-9.

29. Diesel CV, Ribeiro TA, Coussirat C, Scheidt RB, Macedo CA, Galia CR. Coxa profunda in the diagnosis of pincer-type femoroacetabular impingement and its prevalence in asymptomatic subjects. Bone Joint J 2015;97-B:478-83.

30. Gosvig KK, Jacobsen S, Sonne-Home S, Palm H, Troelsen A. Prevalence of malformations of the hip joint and their relationship to sex, groin pain, and risk of osteoarthritis: a population-based survey. J Bone Joint Surg Am 2010;92:1162-9.

31. Kapron AL, Peters CL, Aoki SK, Beckmann JT, Erickson JA, Anderson MB, et al. The prevalence of radiographic findings of structural hip deformities in female collegiate athletes. Am J Sports Med 2015;43:1324-30

32. Anderson LA, Anderson MB, Kapron A, Aoki SK, Erickson JA, Chrastil J, et al. The 2015 Frank Stinchfield Award: radiographic abnormalities common in senior athletes with well-functioning hips but not associated with osteoarthritis. Clin Orthop Relat Res 2016;474:342-52.

33. Nardo L, Parimi N, Liu F, Lee S, Jungmann PM, Nevitt MC, et al. Femoroacetabular impingement: prevalent and often asymptomatic in older men: the Osteoporotic Fractures in Men Study. Clin Orthop Relat Res 2015;473:2578-86.

34. Tsitskaris K, Sharif K, Meacock LM, Bansal M, Ayis S, Li PL, et al. The prevalence of cam-type femoroacetabular morphology in young adults and its effect on functional hip scores. Hip Int 2012;22:68-74.

35. Allen D, Beaulé PE, Ramadan O, Doucette S. Prevalence of associated deformities and hip pain in patients with cam-type femoroacetabular impingement. J Bone Joint Surg Br 2009; 91:589-94.

36. Mariconda M, Cozzolino A, Di Pietto F, Ribas M, Bellotti V, Soldati A. Radiographic findings of femoroacetabular impingement in capoeira players. Knee Surg Sports Traumatol Arthrosc 2014;22:874-8.

37. Larson CM, Sikka RS, Sardelli MC, Byrd JW, Kelly BT, Jain RK, et al. Increasing alpha angle is predictive of athletic-related "hip" and "groin" pain in collegiate National Football League prospects. Arthroscopy 2013;29:405-10. 